\title{
Impact of population density on Covid-19 infected and mortality rate in India
}

\author{
Arunava Bhadra $^{1} \cdot$ Arindam Mukherjee $^{1} \cdot$ Kabita Sarkar $^{2}$
}

Received: 22 August 2020 / Accepted: 3 October 2020 / Published online: 14 October 2020

(c) Springer Nature Switzerland AG 2020

\begin{abstract}
The Covid-19 is a highly contagious disease which becomes a serious global health concern. The residents living in areas with high population density, such as big or metropolitan cities, have a higher probability to come into close contact with others and consequently any contagious disease is expected to spread rapidly in dense areas. However, recently, after analyzing Covid-19 cases in the USA researchers at the Johns Hopkins Bloomberg School of Public Health, London school of economics, and IZA-Institute of Labour Economics conclude that the spread of Covid-19 is not linked with population density. Here, we investigate the influence of population density on Covid-19 spread and related mortality in the context of India. After a detailed correlation and regression analysis of infection and mortality rates due to Covid-19 at the district level, we find moderate association between Covid-19 spread and population density.
\end{abstract}

Keywords Covid-19 Infection and mortality rate $\cdot$ Population density $\cdot$ India

\section{Introduction}

The emergence and continuous spreading of the highly contagious disease Covid-19 leads the World in a very distressing stage. The disease has severe adverse effects on the world economy, as well as on many aspects of human lives like employment, education, physical and mental health of individuals, etc.

In the absence of any precise medicine for the treatment of Covid-19 or any effective vaccine to prevent it, several efforts are made, based on the available pandemic data, in modeling the Covid-19 cases to understand the dynamics of infections (Chen et al. 2020a, b; Roy et al. 2020; Rahman et al. 2020) and subsequently forecasting about the future course of the pandemic for scheming strategies to quickly contain the spreading of the infections by other means like physical distancing, lockdown, etc.

Arunava Bhadra

aru_bhadra@yahoo.com; abhadra@nbu.ac.in

$1 \quad$ High Energy and Cosmic Ray Research Centre, University of North Bengal, Siliguri, WB 734013, India

2 Department of Mathematics, Swami Vivekananda Institute of Science Technology, Dakshin Gobindapur, Kolkata 700145, India
The modeling of transmission of any infectious disease relies on several factors associated with the disease. A number of studies suggest that Covid-19 infection is associated with meteorological factors such as temperature, humidity, wind speed, etc. In particular, below $3{ }^{\circ} \mathrm{C}$, the number of COVID-19 infections in China is found to have a positive linear association with average temperature (Zhu and Xie 2020). A similar correlation between temperature and Covid-19 cases is also found in several Countries and cities, like India (Gupta et al. 2020), Indonesia (Tosepu et al. 2020), Turkey (Şahin 2020), New York (USA) (Bashir et al. 2020), as well as on a worldwide scale (Chen et al. 2020a).

Since coronavirus (SARS-COV-2) transmits via human contact (Chan et al. 2020; Li et al. 2020), the common perception is that Covid-19 spreads rapidly in dense areas, whereas the probability of getting infected is low in areas with low population density. However, after analyzing Covid-19 infection and death rates of 913 urban counties in the USA, a recent investigation by researchers at the Johns Hopkins Bloomberg School of Public Health claims that the infection rate is not linked with population density, whereas death rate is inversely related to population density (Hamidi et al. 2020) except for metropolitan areas where higher infection and higher mortality rates have been noted. The inverse mortality relation with density has been attributed by the authors on the availability of better healthcare 
systems at higher density locations. A very recent study by the researchers from the London school of economics and IZA-Institute of Labour Economics, based on urban Covid-19 cases in the USA, concluded that the timing of the outbreak depends on population density with denser regions leading an early breakout, but both Covid-19 infection and death rates are unrelated with urban population density (Carozzi et al. 2020).

India is a large country with a total population of more than 1.3 billion. It has diverse demographic features. As of 10th September 2020, India is the second maximum Covid19 affected country by the total number of infected people after the USA. The Covid-19 pandemic situation in India thus allows us to cross-check the recent findings (Hamidi et al. 2020; Carozzi et al. 2020) on the impact of population density on Covid-19 spread and related mortality. Probably the first study on the impact of population density (along with several other geographical factors) on the spread of Covid-19 was done by Gupta et al. (2020) in the context of India, but their analysis was based on the Covid-19 data of Indian states up to the 27th April 2020 when total reported Covid- 19 cases was only 29,458 and they considered population density at the state level only.

In India, a major part of total infections and mortality have, at least apparently, been attributed to metropolitan cities such as Mumbai, Delhi, Bangalore, Ahmedabad, Chennai, and Kolkata. The infection and death rates appear to be much lower at remote districts. However, because of the large population of the metropolitan cities, the total infections and mortality are normally higher in those places. Moreover, a strong presence of media reported the Covid19 cases in metropolitan cities in greater detail which might give a false impression that only these cities are dominantly contributing Covid-19 infection and related death.

To have a concrete and reliable idea on the issue in the present work, a detailed analysis of Covid-19-infected and death cases as a function of population density of Indian districts are performed. So far there is no established model about the role of population density on the spread of highly contagious diseases. The findings of the impact of population density on mortality during the 1918 influenza pandemic are debatable. A few researchers find no link between population density and death in 1918 influenza (Chowell et al. 2008; Nishiura and Chowell 2008), whereas a few others claim for a significant positive correlation (Garrett 2010). The Covid-19 pandemic allows us to study the issue in more detail and reliably. The issue is also important in the connection to planning of future towns/cities.

Our findings suggest that till 10th September 2020, Covid-19 infections and mortality in India are moderately correlated with population density; on the average, both the infected and the death cases are higher for large population density.

\section{Data used}

India, the seventh largest country of the world, is a federal union of twenty-eight (28) states and eight (8) union territories at present. The states and union territories are further divided into districts for administrative convenience. At present, there are total of 718 districts in India.

The district-wise Covid-19 cumulative infection and death cases data were taken from the daily bulletins of the Ministry of Health and Family Welfares of Government of India (https://www.mohfw.gov.in/) and the State Governments (such as https://www.wbhealth.gov.in/pages/coron a/bulletin, (West Bengal), https://dgmhup.gov.in/en/covid teamreport, (Uttar Pradesh) https://arogya.maharashtra.gov. in/1175/Novel--Corona-Virus, (Maharashtra) https://stopc orona.tn.gov.in/daily-bulletin/, (Tamil Nadu), https://hmfw. ap.gov.in/covid_19_dailybulletins.aspx (Andhra Pradesh etc.). The daily compiled data from the Central and all the State Government bulletins are also available at api.covid19india.org. We use the data till 10th September, 2020.

The updated corona infected and death data are not available for a few districts such as the districts of Delhi, Goa, and Andaman and Nicobar. Besides that, the cumulative infected and mortality data for districts of Telangana are not reported. We, therefore, could not include those districts in our analysis.

For the district-wise total population and population density, we have used the census 2011 data of the Government of India which are given at https://censusindia.gov. in/. A few new districts have been created since 2011 by splitting, rearranging some districts. For such cases, we have taken the population and density data from the web site of the concerned districts though we could not include all such districts because of lack of data on the district website. We finally consider a total of 600 districts of India in our analysis.

\section{Methodology}

Our primary objective is to explore whether any correlation between Covid-19-infected and mortality cases in India with population density exists or not and if yes, we shall consider modeling between the Covid-19 infection and mortality rate in India (dependent variables) with population density (independent variable).

The computation of the correlation coefficient is the most commonly adopted approach for judging statistical relationship between two variables which essentially measures the degree of (linear) association (Bewick et al. 2003; Kutner et al. 2005). 
For a set of n pair of observations $x_{i}$ and $y_{i}(i$ varies from 1 to $n$ ), the (Pearson) correlation coefficient is defined by

$r=\frac{\operatorname{Cov}(x, y)}{\sigma_{x} \sigma_{y}}$

where $\operatorname{Cov}(x, y)\left(\equiv \frac{1}{n} \sum_{i=1}^{n}\left(x_{i}-\bar{x}\right)\left(y_{i}-\bar{y}\right)\right)$ denotes the cross-covariance of the two variables and $\sigma_{i}(i=x, y)$ is the standard deviation.

It is important to examine whether the association is genuine or not which can be done by considering the null hypothesis test. We shall apply the $F$ test, which compares variances of the two variables and the t-test for the purpose and estimate the $p$ value which essentially gives the probability that the results from the sample data occurred by chance.

We shall also consider linear regression analysis to model the relationship between the infection/mortality rate and population density. The linear regression relies on the relation

$y_{i}=a x_{i}+b+\varepsilon_{i}$

where $x$ and $y$ are the independent and the dependent variables, respectively, $a$ is the slope, $b$ is the intercept on the $y$-axis, and $\varepsilon$ is the error with zero mean value. In the present work, population density is the independent variable, while the infection/mortality rate is the dependent variable. Since the infection/mortality rate must vanish when population density is zero, we have opted $b=0$. However, non-zero $b$ is also considered for completeness of the analysis which incorporates the option that the behavior of $y(x)$ is non-linear near the origin. Using the method of least squares, we estimate the parameters $a^{e}$ and $b^{e}$ from the data. So for a given $x_{j}$ the model estimated $y_{j}^{e}$ will be

$y_{j}^{e}=a^{e} x_{i}+b^{e}$.

The coefficient of determination $\left(R^{2}\right)$ quantifies the amount of variability in dependent variable explained by the model and is defined by the relation

$R^{2}=\frac{\mathrm{SST}}{\mathrm{SSE}}-1$,

where SSE is the sum of squared errors (squared residuals) $\mathrm{SSE}=\sum_{i=1}^{n}\left(\left(y_{i}-y_{i}^{e}\right)\right)^{2}$ and SST is the sum of squared variation in dependent variable about its mean $\mathrm{SST}=\sum_{i=1}^{n}\left(\left(y_{i}-\bar{y}_{i}\right)\right)^{2}$. With the increase in number of regressors, the value of $R^{2}$ always increases. For a meaningful measure of goodness of model fit, adjusted $R^{2}$ is used instead of considering the number of explanatory variables in the model. Microsoft MS Excel software has been exploited to compute the mentioned concerned parameters from the data.

\section{Results and discussion}

The first case of COVID-19 was reported in India on 30th January 2020. By 10th September 2020, the total 4,559,727 people are infected in India by coronavirus out of which $3,539,983$ have recovered, while it is fatal for 76,304 Indians.

Many of the Indian states are quite large and populous. We first address the states separately, but restrict our analysis only to scatter diagram. Since the population of different districts are vastly different, we have considered the total infected and death cases per one million people for each of the districts. Here, we shall show the results for four major states-West Bengal, Maharashtra, Uttar Pradesh, and Tamil Nadu, which are from the East, West, North, and South parts of the country, respectively. The scatter plot of the total (cumulative) infected and death cases per one million people against population density for the stated states are depicted in Fig. 1. It is found that the infection and death rate are higher in metropolitan cities having huge population density in all the cases except Uttar Pradesh where no districts have very large population density. On the other hand, it is noticed that Covid-19 spread and related death are low in districts with low population density. The situation is not very clear in districts with moderate density; the data points spread all over the graphical area with a slight trend to rise of infection and death with density.

Next we consider India as a whole. The scatter plots of the total (cumulative) infected and death cases per one million people against population density for 600 districts of the country are shown in Fig. 2a. Though there are large fluctuations, particularly in the mid population density regions, overall, there is a tendency that both infection and death cases rise with population density.

We estimate the correlation coefficients considering infection and mortality rates as the dependent variables and population density as the independent variable which are found as 0.49 (for infection) and 0.59 (mortality), respectively, indicating moderate positive correlation. For the significance test, the $p$ values are computed which are found very small $\left(\sim 10^{-37}\right.$ for infection rate and even smaller for mortality rate), less than any sensible significant level, and hence the null hypothesis (no correlation) is rejected.

Subsequently, we express the variation of the infection and mortality rates with population density through Eq. (3). The least-square fitting gives $a_{\text {infec }}^{e}=1.26 \pm 0.09$ and $b_{\text {infec }}^{e}=2070 \pm 170$ and $a_{\text {mort }}^{e}=0.04 \pm 0.002$ and $b^{e}{ }_{\text {mort }}=13.2 \pm 4.3$. We also force the straight line to pass through the origin since the infection/mortality rate should be zero when population density vanishes. It is found that 

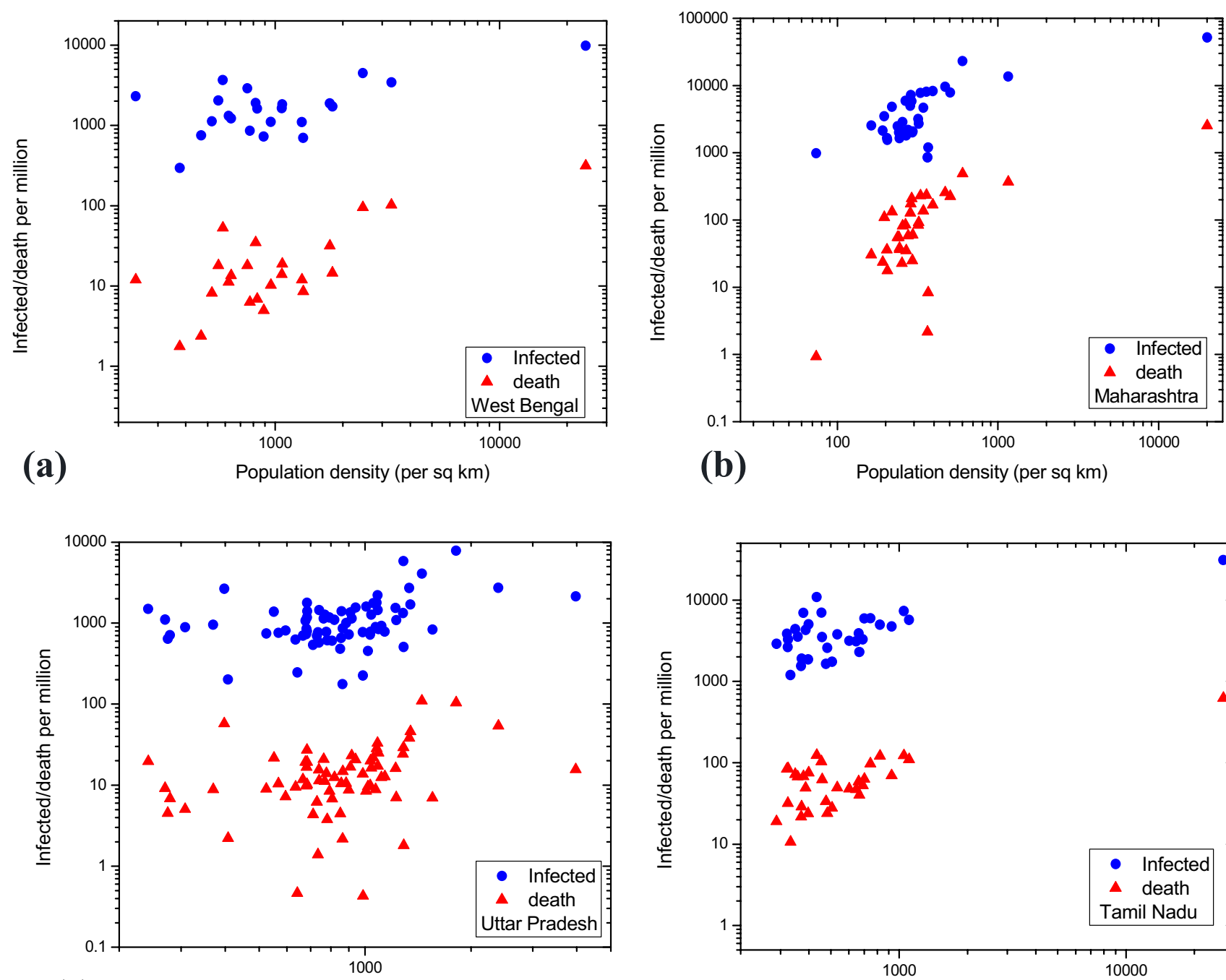

(c)

Population density (per sq km)

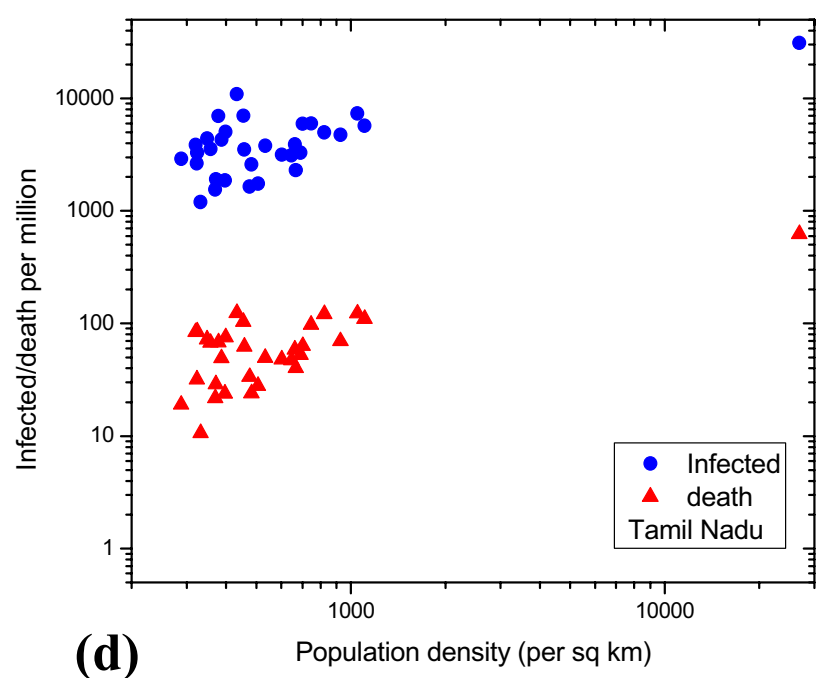

Fig. 1 Variation of infected and death rate due to Covid-19 with population density of districts of a West Bengal, b Maharashtra, c Uttar Pradesh, and d Tamil Nadu

the correlation coefficients are higher and $p$ values are lower in no intercept cases. The linear fit of mortality rate against population density passing through the origin gives the adjusted $R^{2}$ around $41 \%$ that decreases to $23 \%$ when megacities are excluded in the fitting. It is found that the power- law relation does not describe the data well; it gives much lower $R^{2}$ compared to that of the linear fit.

The correlation between population density and infected/ death cases is revealed when we consider small bins in population density and corresponding average infection/ death cases are taken. In the dataset of districts of India, the population density per square $\mathrm{km}$ is found to vary from 3 to 26,903 . We bin the population density in log scale with varying widths; particularly, larger bin widths at high population density are considered so as to have at least a reasonable count of districts (at least 3 ) in each bin. The results are shown in Fig. 3. A linear (proportional) fit describes both the infection and mortality data well.

To verify the claim of researchers that denser regions led an early breakout, we plot the same Covid-19 infection/death variation with population density in Fig. $2 b$, but for the data till 5th July 2020. It appears that with the time the number of infection and death cases are increased, but the overall trend remains mostly unaltered at least till 10th September, 2020.

In the present analysis, we have considered population density obtained by dividing the total population of a district by its total area which implicitly assumes a uniform spatial distribution of populations within a district. The Covid-19 spread and death cases are also considered as uniform. Such assumptions lead to some uncertainty in estimating the correlation between Covid-19 spread and population density. For instance, the population density in the Darjeeling district 

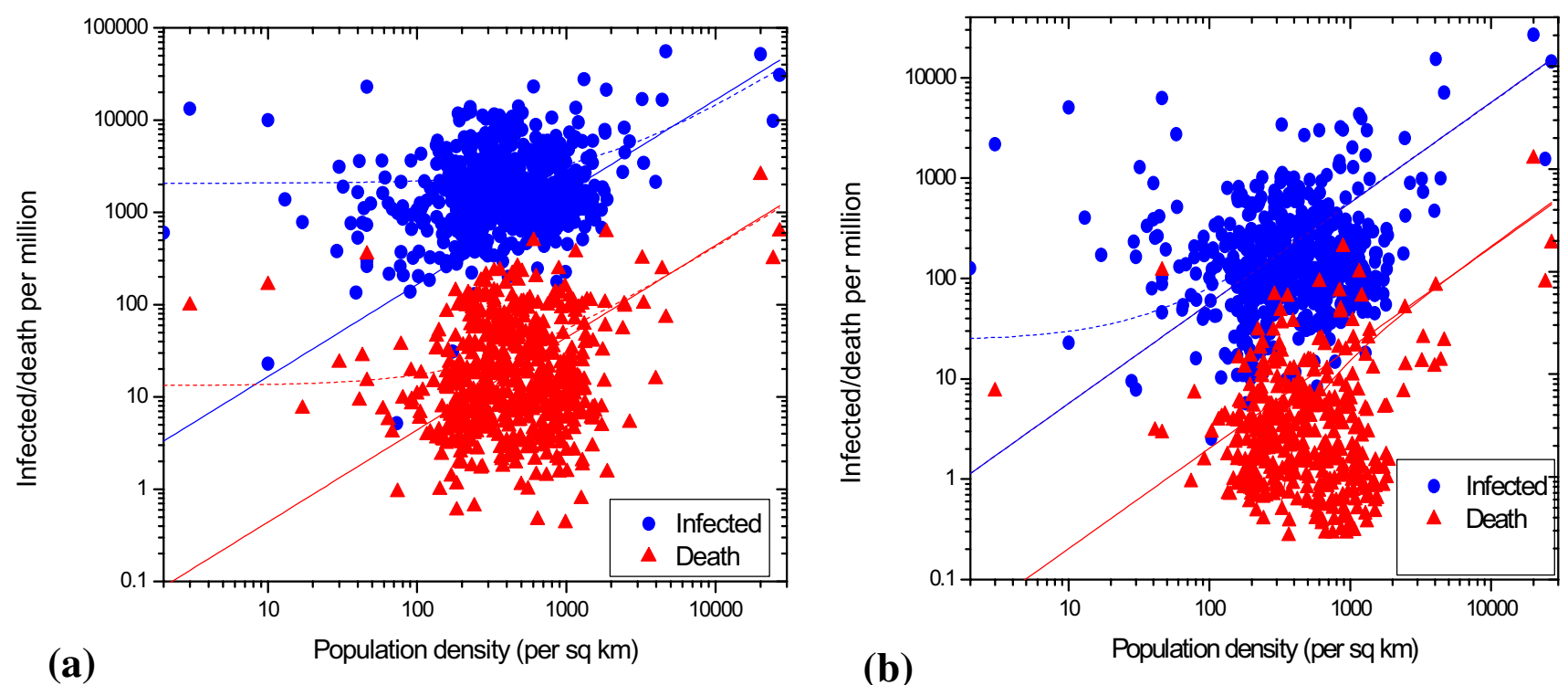

Fig. 2 Same as Fig. 1 but for the whole India, a up to 10th September 2020, b till 5th July2020. The solid and dash lines describe the linear fit of the data with zero and non-zero intercepts, respectively
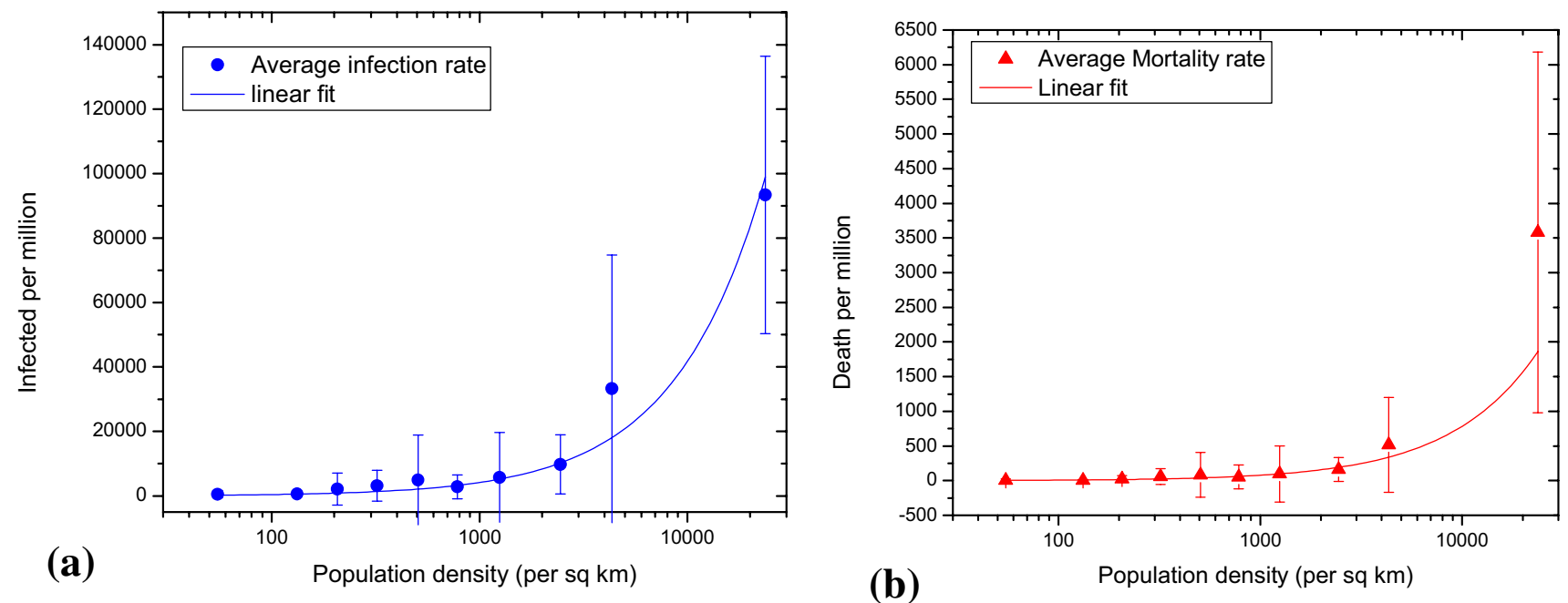

Fig. 3 Variation of averaged infected and death rate due to Covid-19 with population density for the whole country

of West Bengal is among the lowest in the state though the infection and mortality cases are relatively high in the district. This is because of Siliguri, which is one of the congested cities of the state, falls in the Darjeeling district. Most of the infection and mortality cases in the Darjeeling district (and also in the Jalpaiguri district which jurisdiction wise contain a part of Siliguri) are from Siliguri, whereas the major geographical part of the Darjeeling district is the hill area where population density is quite low and thereby the resulting population density of the district is on the lower side. Further study is needed to overcome the stated issues, say by considering the weighted population mean which is a measure of average "experienced" density or considering sub-division as a basic unit for the study. However, the limited availability of necessary data in the public domain is a major hindrance to such improvements.

The $R^{2}$ value of the relation between infection/mortality rate and population density is found moderate, not very high, which implies that only a part of the infection/mortality rate due to Covid-19 can be explained in terms of population density. This can be understood by the facts that the Covid19 spread and related mortality in a district may depend on various other factors including geographical features, economic conditions, prevailing health conditions, genetic 
Table 1 Correlation coefficients and $p$ values

\begin{tabular}{|c|c|c|c|c|c|c|c|c|}
\hline \multirow[t]{3}{*}{ Data } & \multicolumn{4}{|c|}{ Infection } & \multicolumn{4}{|c|}{ Mortality } \\
\hline & \multicolumn{2}{|c|}{ Linear fit } & \multicolumn{2}{|c|}{$\begin{array}{l}\text { Linear fit with no } \\
\text { intercept }\end{array}$} & \multicolumn{2}{|c|}{ Linear fit } & \multicolumn{2}{|c|}{$\begin{array}{l}\text { Linear fit with } \\
\text { no intercept }\end{array}$} \\
\hline & $r$ & $p$ & $r$ & $p$ & $r$ & $p$ & $r$ & $p$ \\
\hline Up to 10 th September 2020 & 0.49 & 0.0000 & 0.58 & 0.0000 & 0.59 & 0.0000 & 0.64 & 0.0000 \\
\hline Up to 5th July 2020 & 0.65 & 0.0000 & 0.67 & 0.0000 & 0.57 & 0.0000 & 0.57 & 0.0000 \\
\hline
\end{tabular}

factors, health infrastructure, policies adopted by the regulating authorities, the average age of the residents of the districts, number of testing, etc. It is already known that Covid-19 has a larger impact on the older population (and population with comorbidity). The share of the older population is not the same in all the districts, neither the total testing number. However, there is no prevailing straightforward and unambiguous method of entangling different probable dependent factors. More research on these aspects are necessary to address the stated issues.

\section{Conclusion}

In conclusion, the present analysis indicates a positive correlation between Covid-19 infection and related mortality with population density as revealed from the correlation and $R^{2}$ analysis, in contrast to the findings by the researchers at the Johns Hopkins Bloomberg School of Public Health, London school of economics, and IZA-Institute of Labor Economics, based on US data. The significance of the correlation is found high from the $p$ values which strongly indicate that the null hypothesis is false in the present case, at least till now.

There is a vast difference in the living conditions of people in the USA and in India which may be responsible for the different behavior of the infected/mortality cases due to Covid-19 with population density in the two countries. The (large) density in India is reflected through the pressing of people against each other in the street, public vehicles, trains, queue for ration, etc. The average area occupied by a family for living in cities of India is also much smaller. The Covid-19 cases were found higher in metropolitan cities even in the USA (Hamidi et al. 2020). So containing a highly infectious disease like Covid-19 is a serious challenge for the country like India unless by any means (maybe by mutation also) the coronavirus (SARS-COV-2) is transformed to a non-lethal variety or an effective vaccine/medicine is discovered (Tables 1, 2).
Table 2 Adjusted $\mathrm{R}^{2}$ in Linear fitting of Infection and death rate

\begin{tabular}{|c|c|c|c|c|}
\hline \multirow[t]{2}{*}{ Data } & \multicolumn{2}{|l|}{ Infection } & \multicolumn{2}{|l|}{ Mortality } \\
\hline & Linear fit & $\begin{array}{l}\text { Linear fit with no } \\
\text { intercept }\end{array}$ & Linear fit & $\begin{array}{l}\text { Linear fit with } \\
\text { no intercept }\end{array}$ \\
\hline Up to 10 th September 2020 & 0.24 & 0.33 & 0.35 & 0.41 \\
\hline Up to 5 th July 2020 & 0.42 & 0.45 & 0.32 & 0.32 \\
\hline $\begin{array}{l}\text { Up to } 10 \text { th September } 2020 \text { but } \\
\text { excluding the megacities }\end{array}$ & 0.11 & 0.38 & 0.32 & 0.23 \\
\hline $\begin{array}{l}\text { Up to } 5 \text { th July } 2020 \text { but excluding } \\
\text { the megacities }\end{array}$ & 0.11 & 0.22 & 0.03 & 0.12 \\
\hline
\end{tabular}


Acknowledgements We are thankful to an anonymous reviewer for useful comments and suggestions.

Funding No funding support is received for the present work.

Data availability We have taken the district-wise Covid-19 cumulative infection and death cases data from the bulletins of Government of India (https://www.mohfw.gov.in/) which is also given at api.covid19india.org.)

\section{Compliance with ethical standards}

Conflict of interest There is no conflict of interest between the authors.

\section{Consent for publication Yes.}

Ethics approval Yes, we have used the data released by the Government of India.

\section{References}

Bashir MF, Ma B, Bilal Komal B, Bashir MA, Tan D, Bashir M (2020) Correlation between climate indicators and COVID-19 pandemic in New York, USA. Sci Tot Environ 728:138835

Bewick V, Cheek L, Ball J (2003) Statistics review 7: correlation and regression. Crit Care 7:451-459. https://doi.org/10.1186/cc2401

Carozzi F, Provenzano S, Roth S (2020) Urban density and COVID-19, discussion paper series, IZA Institure of Labor economics, IZA DP No. 13440

Chan JF-W, Yuan S, Kok K-H, To KK-W, Chu H, Yang J, Xing F et al (2020) A familial cluster of pneumonia associated with the 2019 novel coronavirus indicating person-to-person transmission: a study of a family cluster. Lancet 395:514-523. https://doi. org/10.1016/S0140-6736(20)30154-9

Chen T, Rui J, Wang Q, Zhao Z, Cui J, Yin L (2020) A mathematical model for simulating the phase-based transmissibility of a novel coronavirus. Infect Dis Poverty 9:24

Chen B, Liang H, Yuan X, Hu Y, Xu M, Zhao Y, Zhang B, Tian F, Zhu X (2020) Roles of meteorological conditions in COVID19 transmission on a worldwide scale. medRxiv. https://doi. org/10.1101/2020.03.16.20037168
Chowell G, Bettencourt LM, Johnson N, Alonso WJ, Viboud C (2008) The 1918-1919 influenza pandemic in England and Wales: spatial patterns in transmissibility and mortality impact. Proc R Soc B 275:501-509. https://doi.org/10.1098/rspb.2007.1477

Garrett TA (2010) Economic effects of the 1918 influenza pandemic: implications for a modern-day pandemic. Working paper CA0721.2007. Federal Reserve Bank of St. Louis. https://www. stlouisfed.org/_/media/files/pdfs/community-development/resea rch-reports/pandemic_flu_report.pdf

Gupta A, Banerjee S, Das S (2020) Significance of geographical factors to the COVID-19 outbreak in India. Model Earth Syst Environ. https://doi.org/10.1007/s40808-020-00838-2

Hamidi S, Sabouri S, Ewing R (2020) Does density aggravate the COVID-19 pandemic? J Am Plan Assoc. https://doi. org/10.1080/01944363.2020.1777891

Kutner MH, Nachtsheim CJ, Neter J, Li W (2005) Applied linear statistical models, 5th edn. McGraw-Hill/Irwin, New York

Li Q, Guan X, Wu P, Wang X, Zhou L, Tong Y et al (2020) Early transmission dynamics in Wuhan, China, of novel coronavirusinfected pneumonia. N Engl J Med 382:1199-1207. https://doi. org/10.1056/NEJMoa2001316

Nishiura H, Chowell G (2008) Rurality and pandemic influenza: Geographic heterogeneity in the risks of infection and death in Kanagawa, Japan (1918-1919). New Zealand Med J 121:18-27

Rahman MR, Islam AHMH, Islam MN (2020) Geospatial modelling on the spread and dynamics of 154 day outbreak of the novel coronavirus (COVID-19) pandemic in Bangladesh towards vulnerability zoning and management approaches. Model Earth Syst Environ. https://doi.org/10.1007/s40808-020-00962-z

Roy S, Bhunia GS, Shit PK (2020) Spatial prediction of COVID-19 epidemic using ARIMA techniques in India. Model Earth Syst Environ. https://doi.org/10.1007/s40808-020-00890-y

Şahin M (2020) Impact of weather on COVID-19 pandemic in Turkey. Sci Tot Environ 728:138810

Tosepu R, Gunawan J, Effendy DS, Ahmad LOAI, Lestari H, Bahar H, Asfian P (2020) Correlation between weather and Covid-19 pandemic in Jakarta. Indonesia. Sci Tot Environ 725:138436

Zhu Y, Xie J (2020) Association between ambient temperature and COVID-19 infection in 122 cities from China. Sci Total Environ 724:138201. https://doi.org/10.1016/j.scitotenv.2020.138201

Publisher's Note Springer Nature remains neutral with regard to jurisdictional claims in published maps and institutional affiliations. 